\title{
Discursos e representações
}

\author{
Margarida Fernandes \\ Universidade Nova de Lisboa
}

RESUMO: A PARTIR DA MORTE EM RAZÃO DA FOME, EXAMINA-SE COMO ESSA EXPERIÊNCIA COLETIVA, MARCANTE E PERMANENTE NA MEMÓRIA DO POVO CABOVERDIANO, TRANSFORMA-SE EM TEMA RECORRENTE NA LITERATURA DE CABO VERDE.

ABSTRACT: BASED ON DEATH DUE TO FAMINE, IT IS EXAMINED HOW THIS COLECTIVE EXPERIENCE WHICH IS MARKED AND ALWAYS PRESENT ON CAPE VERDIAN PEOPLE MEMORY. STARVATION HAS BECOME A RECURRENT THEME IN CAPE VERDE LITERATURE.

PALAVRAS-CHAVE: LITERATURA CABOVERDIANA, FOME, FICÇÃO. KEY-WORDS: CAPE VERDIAN LITERATURE, FAMINE, FICTION. 
abo Verde é pioneiro na literatura de expressão portuguesa em África. ${ }^{1}$ Teixeira de Sousa defende que, graças à actividade do clero no sentido de proporcionar aos cabo-verdianos acesso ao ensino, “[...] foi em Cabo Verde onde eclodiu o primeiro movimento literário africano de expressão portuguesa com características regionais acentuadas e inconfundíveis, [...] pela ânsia de afirmar uma identidade nacional[...]." (Teixeira de Sousa, 1985[1984], p. 306). À opção pelas temáticas relevantes no quotidiano de Cabo Verde não será de todo alheia uma afirmação de identidade nacional e cultural que encontra na literatura - e na língua portuguesa - uma forma de se expressar. "A lingua portuguesa [...] nunca foi um obstáculo cultural em Cabo Verde. A capacidade de adaptação à língua portuguesa sem perda da identidade nacional tem sido excepcional neste país." (Teixeira de Sousa, 1990 , p. 219). ${ }^{2}$ Apesar de a prosa se ter socorrido quase sempre da língua portuguesa, na poesia o recurso ao crioulo é freqüente desde os primeiros autores e, em especial, no caso dos poemas musicados que permitiram a divulgação da poesia de origem quer erudita quer popular. Gradualmente, e apesar das muitas discussões a propósito da adopção uma grafia homogénea do crioulo, foram surgindo também romances escritos na língua falada pela população cabo-verdiana. ${ }^{3}$

Na literatura de ficção cabo-verdiana imperam as temáticas locais. A par da emigração, talvez o grande tema dos escritores cabo-verdianos, a temática da morte, e particularmente a mortandade provocada pelas secas, é recorrente. Associada a estes temas - e, talvez, cristalizando-os - a saudade ocupa, também, um lugar destacado.

Nota: todas as citações de obras de ficção aparecem em itálico.

1 José Evaristo d'Almeida, nascido em Portugal, é considerado o autor do primeiro romance caboverdiano, O Escravo (1856).

2 Algumas obras escritas em português, abrangendo um público mais vasto, incluem algumas palavras ou frases em crioulo e são, normalmente, acompanhadas por um glossário. As obras de T.V. da Silva e o romance de Manuel Veiga, Odju d'agu, por exemplo, são integralmente escritas em crioulo. Mais frequente e mais antiga é a poesia em crioulo.

3 A normalização do crioulo escrito tem gerado grande polémica sobre a versão a adoptar. De facto, o crioulo falado também apresenta variações de ilha para ilha. As variações da língua falada nas várias ilhas reflecte a descontinuidade geográfica e exprime-se nas diferentes sonoridades e nos vocábulos. Em 1999 foi aprovada a normalização da escrita do crioulo com a adopção do ALUPEC - Alfabeto Unificado para a Escrita do Cabo-verdiano. 
A literatura de ficção cabo-verdiana das décadas de 30 e 40, foi fortemente influenciada pela literatura brasileira, ${ }^{4}$ através de autores como José Lins do Rego, Graciliano Ramos e Jorge Amado. (Cf. Lopes, 1985[1984], p. 265; Ferreira, 1987, p. 81-105). “[...] o sertão árido do Nordeste brasileiro, flagelado com regularidade pela seca, sofria os mesmos problemas sociais que Cabo Verde." (Brookshaw, 1985[1984], p. 186). A influência destes autores é notória nos claridosos no entanto, a literatura cabo-verdiana evoluiu a um ritmo próprio,

E a partir da Claridade, os escritores islenhos têm procurado captar o universo cabo-verdiano em sua própria dimensão: as estreitezas condicionadas pela terra seca e inóspita, bem como as esperançosas farturas quando as chuvas regressam e as sementes das certezas germinam no ventre da «mamãe-terra» (Caniato, 1985[1984], p. 207).

\section{Morrer de Fome}

Apesar da diferenciação ecológica entre as ilhas, as secas têm atingido, em maior ou menor grau, todas elas (Cf. Miranda, 1985:23). Devido à sua localização geográfica (prolongamento do Sahel) e a factores climáticos, em larga medida associados a essa mesma localização as secas, "conhecidas desde os primórdios da colonização (1462)" (Semedo e Turano, 1997, p. 31), são frequentes no arquipélago.

A característica climática mais temida, e cujos efeitos se apresentam como mais devastadores, é, sem dúvida, o harmatão ou vento de leste, também conhecido por lestada, cujos efeitos Manuel Lopes descreve em Os Flagelados do Vento Leste

Sob o céu ensanguentado, a lestada devorava a superfície verde dos campos. A princípio, a crosta, as folhas e as películas de revestimento dos caules, depois o interior dos rebentos - a parte superior dos pés de milho perdia a elasticidade -

\footnotetext{
4 "Mas a presença da literatura e da cultura brasileiras em Cabo Verde não se reporta apenas a este último período — o da Claridade —, ao contráro do que normalmente se julga.

Os poetas caboverdianos que nasceram no século XIX haviam já experimentado com a mesma devoção e emoção os ventos e os eventos da cultura da nação irmã.” (Ferreira, 1989:171).
} 
até alcançar a estrutura do caule. O vento ardente descia das montanhas, como se as portas do Inferno ficassem para esses lados. Varria a superfície dos campos cobertos de verde viçoso: Por onde passava deixava manchas de amarelo-torrado, folhas doiradas dançando nos ares e um cheiro irrespirável a pimenta em pó. Os milheirais agitavam-se aflitivamente, como pedindo socorro aos homens. Os feijoeiros e as aboboreiras, desamparados, acenavam os compridos caules quase despidos de folhas. Estes eram continuamente arrancadas e levadas em turbilhão. Redemoinhos de poeira vermelha dançavam a sua dança de roda, aqui e ali. (Lopes, 1991[1960], p. 85).

Estes ventos originários do continente africano, mais precisamente do Saara, provocam vendavais devastadores e secas prolongadas. Também Teixeira de Sousa nos dá conta deste fenómeno no romance Ilhéu de Contenda:

Quando clareou o dia, a lestada já havia amainado. Eusébio saiu a averiguar os estragos. A verdura que na véspera cobria as achadas, os cutelos, as ribeiras, transformou-se da noite para o amanhecer num emaranhado de hastes e folhas ardidas. O milheiral que tanto prometia, as faquetas arremangadas prometendo fartura, encontravam-se agora alastrados no chão, de mistura com as cordas de aboboreira e caules de feijoeiro. As árvores pareciam aves depenadas, os galhos contorcendo-se de desespero. O vento leste queimara tudo. Nada, positivamente nada, restava com o viço da véspera. (Teixeira de Sousa, 1983[1978], p. 215).

A fragilidade ecológica e a falta de meios para contrariar os desígnios da natureza, bem como a escassez de outros recursos naturais e económicos, agravam o impacto das crises para uma população que busca sustento na produção agrícola. Se estas características contribuem para uma explicação das crises, não são de descurar as circunstâncias conjunturais, igualmente relevantes.

Se até à época da partilha de África e da implantação do «modo de produção colonial» se assiste a um certo florescimento da economia cabo-verdiana, em grande medida pela inserção do arquipélago no comércio atlântico, a partir de então as ilhas são remetidas a um crescente isolamento, associado às estruturas produtivas da antiga classe senhorial, ao abandono a que a colónia é votada pelo poder central e às condicionantes de natureza geográfica e climatérica, reflecte-se 
num acentuar do declínio da economia insular. Os ciclos de estiagem ganham, assim, uma amplitude crescente e dramática, conduzindo a mortandades e a emigração massivas.” (Estévão, 1985[1984], p. 234).

As ilhas de Cabo Verde têm sido frequentemente assoladas por crises de origens várias e efeitos devastadores e, em particular, por "[...]períodos de estiagens totais ou parciais, que no séc. XIX chegaram a reduzir a população a metade[...]" (Amaral, 1964, p. 180). As consequências demográficas das secas são chocantes. Em 1730 a população das 11 freguesias do arquipélago cifravase em cerca de 25.000 habitantes, em 1775 essa população estava reduzida a 1/3 devido à estiagem (Cf. Amaral, 1964, p. 182).

O número de mortes provocadas pelas secas revela bem as dimensões catastróficas numa população dispersa e reduzida.

Tinham vindo entretanto grandes secas, grandes fomes. Começaram por volta de 1830, e duraram até 1834. Nenhum outro período de fomes anteriores matara tanta gente nas ilhas, calcula-se que morreram durante esses anos trinta e três mil e seiscentas pessoas, das quais quatro mil eram escravos. (Barreno, 1998[1994], p. 265).

Entre 1900 e 1947 estima-se que morreram 82 mil pessoas "Em todo este período a taxa de mortalidade pela fome, nas fases mais agudas, rondou os 17,6\% a 22,4\%, em relação à população recenseada!” (Carreira, 1984[1977], p. 10$).^{5}$

As fontes de alimentação incluíam tudo aquilo que parecesse remotamente comestível. "E foi então que o povo do interior da ilha [da Boavista] se lembrou da potona” (Almeida, 1994:221). ${ }^{6}$ O seu consumo tinha consequências nefastas " "[...] a mais gente morria como de peste pelas ervas e sevandilhas que comiam»" (Padre Barreira, ânua de 1611, citado por Carreira, 1984[1977], p. 17/8; Vieira,

5 A fome de 47 foi a última que provocou grande número de vítimas. A maioria das descrições na literatura de ficção referem-se a este período.

6 "A potona é um pequeno tubérculo as duas anteriores [jêjê e janglan] são gramíneas. Tudo isso com pouco valor nutritivo." (Carreira, 1984[1977]:34). 
1987, p. 17). Em São Nicolau, o "Povo pegou fedegosa” e muita gente morreu. Gente de S. Vicente fez morna. Morna de fédegosa." (Ferreira, 1980[1962], p. 56).

"Fèdegosa bô é mau

Bô Matâ nha mamãe

Bô matâ nha papai" (Cf. Ferreira, 1980[1962], p. 57). ${ }^{8}$

No desespero da fome "Raízes, ervas, tudo era comida." (Ferreira, 1980 [1962]: 56).

O conhecimento prévio dos efeitos da ingestão dessas ervas nem sempre era um dissuasor eficiente: “[...] Encontrávamos, por vezes, algumas ervas, plantas insólitas. Sabíamos de gente que morrera ao comer certas ervas, certas plantas. Mas a fome era intensa e o meu pai comia e dava-me a comer [...]" (Didial, 1989, p. 16). No desespero da fome "Raízes, ervas, tudo era comida." (Ferreira, 1980[1962], p. 56).

As conseqüências das secas na produção agrícola reflectem-se tanto na escassez de mão-de-obra e na destruição dos meios de subsistência como na desvalorização das próprias explorações. As repercussões desta situação são recorrentes e encontram-se relatadas mesmo em épocas muito remotas. Uma propriedade de Santa Cruz (Ilha de Santiago) vendida em 1619 por metade do seu valor ressente-se ainda das crises de 1609-1611:

"As secas, descapitalizando as explorações agrícolas de mão-de-obra (pesas) e de espécies vegetais pertinentes (árvores de algodão), desorganizando e refreiando a produção («as mores partes de terras a monte»), constituem sem dúvida uma fonte de empobrecimento e de falências. No exemplo citado, a seca produziu a depreciação em 50\% do valor venal da exploração agrária isto mesmo depois de oito anos da sua ocorrência” (Silva, 1996[1995] p. 109).

\footnotetext{
7 "Planta quenopodiácia (chenopodium vulvaria) cujas sementes torradas substituem o café." (Ferreira, 1980[1962]:194). Orlanda Amarílis dálhe outra grafia e compara-a não ao café mas ao chá “[...] Só se for do tempo de chá de fedagosa." (Amarílis, 1991[1974]:11). Segundo Miranda "O povo da Ilha de Santo Antão, na esperança de sobreviver, fizera recurso a sementes de uma planta leguminosa, amarga e prolixa, que, por ser venenosa, espalhara a morte entre os mais necessitados.” (1989:264).

8 Fedegosa tu és má // Mataste a minha mamã // Mataste o meu papá. (tradução minha).
} 
As crises provocavam também alterações profundas na distribuição da propriedade e no tecido social:

"As terras mudavam de dono no fim de cada período de seca. Os pequenos proprietários vendiam as suas parcelas para conseguirem meios de escapar à fome ou para emigrarem. Muitos dos grandes proprietários levavam uma vida luxuosa que os conduziu à miséria deixando miseráveis descendentes que engrossavam a massa de candidatos à emigração ou de rendeiros dos que compravam as terras dos seus pais." (Semedo e Turano, 1997, p. 53).

Mesmo perante tão calamitosa situação havia quem aproveitasse para enriquecer. Havia quem comprasse, a preços irrisórios, boas terras de cultivo e outros bens que muitos se viam obrigados a vender

"[...] A primeira propriedade que comprei foi esta, naquele ano das bexigas. Comprei-a barato. Depois fui trabalhando, trabalhando, veio a fome no ano do cometa, aproveitei a ocasião para comprar as outras terras." (Teixeira de Sousa, 1992, p. 236).

Os famintos vendiam tudo o que tinham - móveis, telhas, terras - o suor da vida inteira. A própria vida. Tudo vendido por preços irrisórios ou a troco de géneros que mal acalentavam a fome por mais uns dias.

“[...] Vendi minha hortinha. Sr. Joãozinho comprou foi canseira de fábrica onde trabalhei anos sem conta. Ele comprou a minha casa onde nasceram meus meninos, tudo quanto ajuntei debaixo de suor e fadiga, por três contos e duzentos mil réis.” (Romano, 1983[1962], p. 75).

Enriqueciam alguns, pouco escrupulosos e com sentido de oportunidade, que não deixaram escapar um bom negócio, como o Sr. Joãozinho. Também Sebastião Cunha, personagem de Hora di Bai, senhor de

"[...] uma das casas mais ricas de São Vicente. Riqueza acumulada ao longo de anos, em terras, imóveis e dinheiro depositado nos bancos. E ainda na sua casa comercial por onde decorriam e floresciam os mais variados negócios [...] 
não lhe perdoavam os processos de agiota. E muito menos que numa época de fome, como aquela, mantivesse os celeiros fartos, os géneros ao preço que lhe apetecia, $e$ negados a quem não podia comprá-los com dinheiro na mão. Por isso a população necessitada odiava-o. Nem um lhe perdoava." (Ferreira, 1980[1962], p. 103-104).

Os especuladores beneficiavam da situação: açambarcavam para vender com lucro exagerado e sem remorso.

"Não desejo mal ao povo. Sou comerciante. O senhor conhece bem o que são estas coisas. Faço cá a minha vida, mas franqueza, franquezinha, a chuva que é bem para uns pode ser mal para outros: cada um se vai governando como pode. A seca pode beneficiar muita gente...

$[\ldots]$

Pra quê fingir? Toda a gente aliás sabe que tenho os armazéns a abarrotar de milho. [...] tenho armazenados cento e cinquenta contos de réis em milho. $\mathrm{O}$ comércio é um jogo, o senhor sabe muito bem, e quem joga não quer perder. Pelo preço que comprei o milho, é para obter um lucro de cem por cento.[...]" (Lopes, 1982[1956], p. 118-119).

As medidas de assistência, fosse ela estatal, promovida pelas igrejas ou por particulares, eram escassas, e particularmente ineficazes, para acudir a tantas bocas famintas.

"À porta das casas de Assistência onde se distribuía mantimento, as filas aguardavam as rações numa impaciência irritada[...].

Os guardas cumpriam ordens, a brandir chicotes, batendo em esqueletos ambulantes, muitas vezes facilitando a morte, a prosseguir na cruzada de exterminação dos pedintes doentios [...]

$\mathrm{E}$ as filas de carregadores chegavam com mais mantimentos em sacos cosidos, empilhando-os nos depósitos da Assistência.

Olhos seguiam a comida que chegava e desaparecia nos alçapões, sob a vigilância dos polícias[...].

Quem teria paciência para esperar até à quinzena nova? - perguntavam entre si à espera de uma resposta consoladora que não vinha porque ninguém tinha 
a certeza de aguentar com vida mais uma quinzena." (Romano, 1983[1962], p. $146-147){ }^{9}$

As mortes, por disenteria, tuberculose, febre tifóide e outras doenças - ou por fome, pura e simples - atingiam tais proporções que já não era possível dar um enterro digno à maior parte das pessoas.

"O sino soava rouco de tanto dobrar a finados. Padre Horácio encomendava dois, três mortos de uma assentada. Almas e alminhas. A padiola mortuária tinha fixado residência no ombro dos lavradores. Em tempos de boaságuas, os defuntos eram dados à terra com compostura, mas, agora, aqueles a quem o pão indeferia presença no meio dos vivos, eram atirados para a vala comum, cavada na lufa-lufa, mesmo sem mudar de trapos. À gente de coração fraco, doía ouvir falar de enterro. Planeta só dava para se livrar dos mortos. Um mal de barriga, um desmaio, e lá surgia a padiola. Seguia-se a jornada até à igreja mais próxima à caça de encomendação. Uns morriam a caminho do seu próprio enterro, outros eram dados à terra com fôlego ainda teimosamente colado ao peito. O medo à padiola, que trabalhava sem descanso e sem cerimónia, unia as criaturas. Minguava de dia para dia o número daqueles que podiam garantir o adiamento da sua própria viagem." (Silveira, 1991, p. 69).

A padiola fazia parte das medidas sanitárias que visavam impedir a propagação de doenças associadas aos cadáveres expostos. O poema Casebre de Jorge Barbosa é cruamente elucidativo.

Foi a estiagem.

E o silêncio depois.

Nem sinal de planta

Nem restos de árvore

No cenário ressequido da planície

[...]

Foi a estiagem que passou.

Nestes tempos

9 Devido à queda de um paredão, a assistência nas fomes dos anos 40 ficou marcada por um acidente que ficou conhecido como "o desastre da assistência", Carreira, 1984[1977]: anexo (fotos); Ver também Mascarenhas, 1988:45. 
Não tem descanso

A padiola mortuária da regedoria.

Levou primeiro

O corpo mirrado da mulher

Com o filho nu ao lado

De barriga inchada

Que se diria

Que foi de fartura que morreu.

$\mathrm{O}$ homem depois

Com os olhos parados

Abertos ainda.

Tão silenciosa a tragédia das secas nestas ilhas!

Nem gritos nem alarme

- Somente o jeito passivo de morrer!

$[\ldots]$

(Jorge Barbosa, 1956 in Ferreira, 1975, p. 100)

Aqueles que ainda podiam, iam carregando os cadáveres para os enterrar em covas pouco fundas - que os cães e as aves de rapina desenterravam - ou para os lançar pelas arribas. "As famílias não possuíam meios, nem forças físicas para fazer transportar os seus parentes falecidos." (Carreira, 1985, p. 22). A partir do momento em que deixava de haver quem lhes fizesse um enterro digno da sua condição humana, muitos dos famintos que morriam pelos caminhos jaziam insepultos (Cf. Mariano, s.d.; Romano, 1983[1962], Lopes, 1991[1960], Carreira, 1985, p. 22-23).

"[...] acolá, a dois passos, o corpo de um petiz esverdeando-se fora da cova que não foi concluída, os corvos a desenharem círculos à volta, estendendo o bico, a tocarem a ponta da asa no defunto, certificando-se da sua imobilidade. Mais além um velho, as gengivas à mostra, formigas entrando e saindo pelas narinas, pela boca, pelos ouvidos, os braços entre os joelhos, o ventre como um tambor." (Romano, 1983[1962], p. 55).

A convivência frequente com o macabro não causa, naturalmente, insensibilidade perante a morte. A indignidade de morrer de fome, da "[...] morte 
colectiva, a morte anónima. Morto morrido." (Ferreira, (1967[1948]), p. 33). ${ }^{10}$ é recordada com angústia e horror pelos mais velhos. A despersonalização da morte ocorre em situações de mortandade, como é referido por Mohen, para as pestes medievais. A ordem social e os ritos tradicionais são perturbados.

“[...]La mort frappait si fort et si vite que le nombre des cadavres, en s'accroisant rapidement, abolissait la mort personalisé. Les rites de la maladie qui unissaient le patient et son entourage disparaissaient: les phases de la célébration funéraire, la toilette du mort, la veillée autour du corps avec la déploration ou lamento, la mise en bière et le banquet funébre, la procéssion jusqu'au cimetière, l'enterrement ne pouvaient plus avoir lieu.[...]" (Mohen, 1995:235/6). ${ }^{11}$

O desespero da fome implicava, não raras vezes, o afrouxamento dos laços de solidariedade e a alteração das regras de conduta moral e social. ${ }^{12}$ Mesmo as normas mais sagradas eram quebradas, como comentam Moacyr Rodrigues e Isabel Lobo, relativamente à morna da fédegosa, " [...] A fome era tanta que os pais comiam e não davam aos filhos. Esses ficavam para contar como tinha sido a morte dos pais.” (Rodrigues \& Lobo, 1996, p. 84). A fome não dá tréguas.

“[...] levou a mão à boca e aí enfurnou as bolachas, na esperança de as comer sem partilhas, ao mesmo tempo que se defendia dos outros, gesticulando e grunhindo como um suíno. Foi nesses movimentos que sufocou, os olhos esbugalhados, a respiração faltando e ele na calçada da Praça aos esticões. Na garganta uma bolacha engasgada. Os outros rodearam-no à espera que ele morresse. Finalmente, um deles, meteu-lhe

10 A expressão "morto morrido" ou "morte morrida" opõe-se a "morte matada". A "morte matada" implica a morte provocada. A "morte morrida" pressupõe a morte natural de indivíduos velhos e/ou doentes. Veja-se em Morte e Vida Severina, de João Cabral de Melo Neto "[...] essa morte foi morrida/ / ou foi matada? / / Até que não foi morrida/ / irmão das almas, / / esta morte foi matada, / / numa emboscada,[...]" (Neto, 1967:9). Ver também Ferreira, 1984[1971]:32 e Ferreira, 1980[1962]:35.

11 “[...] a morte chegava tão forte e tão depressa que o número de cadáveres, ao aumentar rapidamente, abolia a morte personalizada. Os ritos da doença que uniam o paciente e os seus acompanhantes desapareciam: as fases da celebração funerária, a higiene do morto, o velório em volta do corpo com a deploração ou lamento, a transferência para o caixão e o banquete fúnebre, a procissão para o cemitério, o enterro não podiam já ter lugar.[...]" (minha tradução)

12 A tese da quebra total de moralidade e de solidariedade em situações de fome e miséria é levada a extremos na obra de Turnbull sobre os Ik do Uganda (Vd. Turnbull, 1989[1973]). 
os dedos pelos gorgomilhos e retirou o bocado que, num abrir e fechar de olhos devorou antes que os companheiros the tombassem em cima." (Romano, 1983[1962], p. 78).

A fome conduzia à marginalidade: roubos, prostituição, e violência (Cf. Carreira, 1984[1977], p. 18). "Acabara-se tudo, a amizade, a vergonha, só havia a raiva da fome." (Teixeira de Sousa, 1998[1972], p. 58).

A situação mais extrema em tempos de fome são os casos de antropofagia face às quais as autoridades adoptaram medidas punitivas nas secas de 177376 (Cf. Miranda, 1985:23). Na literatura de ficção, Gabriel Mariano relata o caso de Luzia

“[...] da Fajã de Baixo. Um dia saiu para a Vila com seu filho nas costas. Não tinha botado comida no corpo passava mais de uma semana. Andou, andou [...] cada vez podendo menos. Quando chegou na Assomada do Vento sentouse para descansar. Tirou o filho das costas. O filho estava morto. Luzia não o enterrou. Ninguém viu o corpo do menino. Luzia tinha fome. Só ficaram os ossos..." (Mariano, s.d., p. 97).

\section{Uma parceria possível?}

Não será surpreendente que a morte durante as secas ocupe um lugar de destaque na literatura Cabo-verdiana. Se isso acontece, é precisamente porque esta experiência colectiva é marcante e permanece na memória do povo. A morte durante as secas - paradigma da "má morte" no contexto cabo-verdiano - altera temporariamente o equilíbrio social. Obriga à deslocação de muitas pessoas, que deixam as suas terras em busca de sustento, e leva à não observância das regras de conduta estabelecidas. Esta ruptura afecta o tecido social e reflecte-se na quebra dos laços de solidariedade, indiciando a incapacidade do grupo em manter a sua coesão, ao mesmo tempo exacerba as clivagens sociais. A morte, nestas circunstâncias, afecta, sobretudo, os mais desfavorecidos, impotentes para fazer face à calamidade, por ausência de recursos materiais. Cabo Verde é um desafio constante. "Uma tragédia contínua numa terra flagelada pelas estiagens, onde viver é um acto heróico.” (Caniato, 1985[1984], p. 211). Uma maldição a que o povo, tenazmente, resiste. 
Muito embora a literatura de ficção não esteja sujeita aos constrangimentos dos relatos factuais, podendo até recusá-los como defende José Eduardo Agualusa ao afirmar que "... quantos menos factos melhor, a realidade atrapalha a ficção.” (Agualusa, 2000, p. 57). A literatura constrói um discurso relevante e com sentido onde os elementos ficcionais enquadram, mesmo que de forma alterada, elementos próximos do mundo real, o que proporciona legitimidade simbólica e estruturante à obra literária. Como refere Giovanni Ricciardi, “[...] O escritor é, pois, um criador, mas, ao mesmo tempo, a sua obra está, toda ela, mergulhada no momento histórico que a origina." (Ricciardi, 1971, p. 80). Para Ruy Duarte de Carvalho “..... (a ficção como processo sempre me assustou, mesmo sabendo que nenhuma ficção o é. Uma acção que se invente é sempre uma acção possível, real, portanto.)" (Carvalho, 1992[1977]:20).

A liberdade do ficcionista não subverte, inevitavelmente, os factos registados nos documentos oficiais ou noutras fontes - também elas, interpretações da realidade. Os trabalhos de investigação levados a cabo por cientistas sociais revelam, por vezes, uma coincidência surpreendente com relatos elaborados no âmbito da literatura de ficção, demonstrando um paralelismo possível entre a ficção e a realidade. Não raras vezes, as fontes de uns e de outros têm proveniências comuns. Como defende Jean Copans, no processo de criação literária "O escritor vai-se transformando em investigador para descrever uma certa realidade utilizando os documentos e as técnicas do trabalho de campo.”(Copans, 1981[1971], p. 37). Efectivamente, “[...] la littérature constitue pour les sciences sociales, en tout ou partie, un corps de données, une ressource cognitive et un modèle d'énonciation. [...] (Lassave, 2002, p. 37). ${ }^{13}$

Mais do que produto de um momento histórico, as literaturas africanas, e não só as de língua portuguesa, transportam em si uma matriz da oralidade na forma como se escrevem, o que constitui a marca de culturas em que a palavra dita se impõe, quer na poesia quer na prosa. (Cf. Leite, 1998).

A literatura de ficção permite tecer um fio condutor entre a ficção e a realidade ao evocar, de forma eloquente, a relevância de que se revestem estes temas na sociedade cabo-verdiana. As representações da morte na literatura

13 “[...] a literatura constitui para as ciências sociais, no seu todo ou em parte, um corpo de dados, um recurso cognitivo e um modelo de enunciação. [...]” (Tradução minha). 
de ficção correspondem a uma mundividência apoiada nos padrões culturais da sociedade envolvente. Não será, por isso, particularmente relevante apurar "a verdade dos factos" relatados porque, efectivamente, a "verdade" é sempre ilusória independentemente da fonte a que recorrermos. A literatura de ficção constitui uma forma de expressar pontos de vista que acabam por influenciar as formas de pensar, agir e sentir da população de quem, por vezes, se torna porta-voz.

\section{Referências bibliográficas:}

AGUALUSA, José Eduardo. Um Estranho em Goa. Lisboa: Cotovia, 2000.

AMARAL, Ilídio. Santiago de Cabo Verde: a terra e os homens. Lisboa: Memórias da Junta de Investigação do Ultramar, 1964.

BROOKSHAW, David "A Busca da Identidade Regional e Individual em Chiquinho e o Movimento da Claridade", in Les Littératures Africaines de Langue Portugaise: à la recherche de l'identité individuelle et nationale. Actes du Colloque International, Paris, 2829-30 Nov., 1 Dec. 1984. Paris : Fundação Calouste Gulbenkian/Centre Culturel Portugais, 1985, p. 185-191.

CANIATO, Benilde Justo Lacorte (1985[1984]) “Hora di Bai: Típica Síntese Caboverdiana”, in Les Littératures Africaines de Langue Portugaise: à la recherche de l'identité individuelle et nationale. Actes du Colloque International, Paris, 28-29-30 Nov., 1 Dec. 1984. Paris: Fundação Calouste Gulbenkian/Centre Culturel Portugais, 1985, p. 207-213.

CARREIRA, António. Cabo Verde: aspectos sociais, secas e fomes do século XX. Lisboa: Ulmeiro, 1984[1977].

CARREIRA, António. Demografia caboverdeana: subsidios para o seu estudo (1807/ 1983). Praia: Instituto Cabo-verdiano do Livro, 1985.

CARVALHO, Artur Sem Titulo, (texto dactilografado gentilmente cedido pela Dra Assunção Carvalho), sem local, sem data, (inédito)

CARVALHO, Ruy Duarte de. Como se o mundo não tivesse leste. Lisboa: Veja, 1982.

COPANS, Jean et al. Antropologia, ciência das sociedades primitivas? Lisboa: Edições 70, 1981.

ESTÉVÃO, João António. "Literatura Cabo-verdiana e Investigação em Economia Política: O Exemplo de Ilhéu de Contenda de Teixeira de Sousa", in Les Littératures Africaines de Langue Portugaise: à la recherche de l'identité individuelle et nationale. Actes du 
Colloque International, Paris, 28-29-30 Nov., 1 Dec. 1984. Paris: Fundação Calouste Gulbenkian/Centre Culturel Portugais, 1985, p. 233-240.

FERREIRA, Manuel. O Discurso no Percurso Africano I. Lisboa: Plátano Editora, 1989.

FERREIRA, Manuel (Org.). No reino de Caliban: Antologia Panorâmica da Poesia Africana de Expressão Portuguesa - Cabo Verde e Guiné-Bissau. Lisboa: Seara Nova, 1975, vol. 1.

LASSAVE, Pierre. Sciences sociales et littérature. Paris : Presses Universitaires de France, 2002.

LEITE, Ana Mafalda. Oralidades e escritas nas literaturas africanas. Lisboa: Edições Colibri, 1998.

LOPES, Leão. "Para uma Caracterização da Cultura Cabo-verdiana: Tópicos para uma Identidade", in Les Littératures Africaines de Langue Portugaise: à la recherche de l'identité individuelle et nationale. Actes du Colloque International. 28-29-30 Nov., 1 Dec. 1984. Paris: Fundação Calouste Gulbenkian/Centre Culturel Portugais, 1985, p. 263-267.

MIRANDA, Nuno. “As 'Crises' de Cabo Verde”. In História, n 81, Julho, 1985. p. 22-23.

MOHEN, Jean Pierre. Les Rites d'au-delà. Paris : Éditions Odile Jacob, 1995.

NETO, João Cabral de Melo. Morte e vida severina (Auto de natal pernambucano). Rio de Janeiro: Sabiá, 1967.

RODRIGUES, Moacyr; LOBO, Isabel. A morna na literatura tradicional: fonte para o estudo histórico-literário e a sua repercussão na sociedade. Mindelo: Instituto Cabo-verdiano do Livro e do Disco, 1996.

SEMEDO, José Maria; TURANO, Maria R. Cabo Verde: o ciclo ritual das festividades da tabanca. Praia: Spleen Edições, 1997.

SILVA, António Leão C. Histórias de um sahel Insular. Praia: Spleen Edições, 1996.

SILVEIRA, Onésimo. Consciencialização na literatura cabo-verdiana. Lisboa: Casa dos Estudantes do Império, 1963.

TEIXEIRA DE SOUSA, Henrique (1985[1984]) "A Igreja e a Literatura em Cabo Verde", in Les Littératures Africaines de Langue Portugaise: à la recherche de l'identité individuelle et nationale. Actes du Colloque International, 28-29-30 Nov., 1 Dec. 1984. Paris: Fundação Calouste Gulbenkian/Centre Culturel Portugais, 1985, p. 303-308.

TIOFE, T. T. "Arte poética e artefactos poéticos em Cabo Verde. Reflexões sobre os últimos 50 anos da poesia cabo-verdiana", in Les Littératures Africaines de Langue Portugaise: à la recherche de l'identité individuelle et nationale. Actes du Colloque Interna- 
tional, Paris, 28-29-30 Nov., 1 Dec. 1984. Paris : Fundação Calouste Gulbenkian/ Centre Culturel Portugais, , 1985, p. 309-315.

TURNBULL, Colin. The mountain people. Londres : Paladin, 1989.

VIEIRA, Henrique Lubrano de Santa-Rita. História da medicina em Cabo Verde. Praia: Instituto Cabo-verdiano do Livro e do Disco, 1987.

Obras de literatura de ficção cabo-verdiana

ALMEIDA, Germano. A Ilha Fantástica. Lisboa: Caminho, 1994.

ALMEIDA, José Evaristo de. O escravo. Linda-a-Velha: ALAC, 1989.

AMARÍLIS, Orlanda. Cais-do-Sodré Té Salamansa. 2 ed. Linda-a-Velha: ALAC, 1991. BARRENO, Maria Isabel . O senhor das ilhas. Lisboa: Caminho, 1998.

DIDIAL, G.T. O estado impenitente da fragilidade. Praia: Instituto Cabo-verdiano do Livro e do Disco, 1989.

FERREIRA, Manuel. Morna. 2 ed. Lisboa: Início, 1967.

FERREIRA, Manuel. Hora di bai. 4 ed Lisboa: Plátano, 1980.

LOPES, Manuel. Chuva braba. Lisboa: Edições 70, 1982.

LOPES, Manuel. Os flagelados do vento leste. 3 ed. Lisboa: Vega, 1991.

MARIANO, Gabriel. Vida e morte de João Cabafume. Lisboa: Veja, s.d.

ROMANO, Luís. Famintos. Lisboa: Ulmeiro, 1993.

SILVEIRA, Onésimo. A Saga das As-Secas e das Graças de Nossenhor. Mem Martins: Europa-América, 1991.

TEIXEIRA DE SOUSA, Henrique. Ilhéu de contenda. Mem Martins: Europa-América, 1983.

TEIXEIRA DE SOUSA, Henrique. Djunga. Mem Martins: Europa-América, 1990.

TEIXEIRA DE SOUSA, Henrique. Contra mar e vento. Mem Martins: Europa-América, 1998.

VEIGA, Manuel. Odju d’Agu. Praia: Instituto Cabo-verdiano do Livro, 1987. 